Revista Luna Azul - EL CONCEPTO “MORADA” COMO CATEGORÍA POSIBLE P... Página 1 de 10

\title{
EL CONCEPTO "MORADA" COMO CATEGORÍA POSIBLE PARA LA FUNDAMENTACIÓN DE UNA ÉTICA AMBIENTAL
}

\author{
Juan Carlos Aguirre García (1) \\ Manizales, 2007-11-07 (Rev. 2007-12-15) \\ RESUMEN \\ El presente escrito hace un recorrido por el libro del filósofo Emmanuel Levinas \\ Totalidad e Infinito, con el fin de analizar su concepto "Morada", y establecer, a modo \\ de esbozo, unos puntos para la discusión ética en torno al medio ambiente. Comienza \\ con una introducción en la que se consignan algunos datos biográficos del autor; \\ continúa con una exploración crítica del concepto y culmina con unas reflexiones \\ posibles a la hora de discutir desde el campo de la filosofía, especialmente de la \\ fenomenología, cuestiones éticas sobre el medio ambiente.
}

\section{PALABRAS CLAVE}

Morada, rostro, representación, cuerpo, trabajo.

\section{THE CONCEPT OF "DWELLING" AS A POSSIBLE CATEGORY FOR THE FUNDAMENTATION OF AN ENVIRONMENTAL ETHICS}

\begin{abstract}
The present article constitutes a journey through the book of the philosopher Emmanuel Levinas, entitled Totality and Infinite, with the purpose of analyzing his concept of "dwelling", and as a review of some points for the ethical discussion centered on the environment. It begins with an introduction in which the author's biographical data is consigned; it continues with a critical exploration of the concept and it ends with some possible reflections when discussing, from a philosophical point of view, especially phenomenology, ethical questions on the environment.
\end{abstract}

\section{KEY WORDS}

Dwelling, face, representation, body, work.

\section{INTRODUCCIÓN}

La reflexión medioambiental, al menos en su línea filosófica, ha comprendido que dentro de sus núcleos fundantes se encuentra la consideración de referentes estéticos que, como bien lo anuncia Heidegger, permiten obturar el pensamiento calculador que asume la naturaleza como depósito, como disposición al proyecto técnico (2). Mucho se ha discutido al respecto, no sólo desde la filosofía del medio ambiente, sino desde algunos sectores considerables de la filosofía de la técnica o la tecnología. En ocasiones, la recurrencia a la estética se exagera en desmedro de otras consideraciones, $v$. gr. la ética, que juega un papel igualmente preponderante a la hora de entablar relaciones de cuidado y responsabilidad con la vida en todas sus manifestaciones.

Conscientes de esto, el presente escrito aborda el concepto "Morada" desde la perspectiva del filósofo Emmanuel Levinas. Con este fin, se explorará una de sus principales obras: Totalidad e Infinito. No significa esto que la centralidad de la atención lleve al olvido de sus otros trabajos, en los cuales se encuentran matices interesantes de la cuestión. La exploración del concepto llevará a proponerlo como una categoría fundamental a la hora de analizar una ética ambiental. 


\begin{abstract}
Antes de iniciar la exposición, es preciso decir dos palabras acerca de Levinas, filósofo que cada vez concita más lectores y sirve de referencia a múltiples análisis. A pesar de su origen lituano, Levinas asume toda la tradición judía que hereda de su familia; muy joven se traslada a Francia y allí absorbe la filosofía del momento, la cual estaba en plena ebullición. Fenomenólogo de corazón (3) , traductor de Husserl y alumno de Heidegger, este filósofo multicultural como lo denomina Andrius Valevičius (4), se separa de sus maestros e inicia un camino en el que se trenza razón y fe, Israel y Atenas, holocausto y esperanza, sufrimiento y responsabilidad por el otro. Si la primera palabra habla de su vida, la segunda nos remite a su obra, ligada esencialmente a la primera. Para Levinas, el privilegio de la conciencia representativa ha hecho que todo sea susceptible de ser analizado en términos de Luz (5) ; esto hace que lo exterior a mí sea representable en mi conciencia, tematizable desde mi perspectiva y, en últimas, englobable en un yo autárquico. Frente a este dominio de la conciencia, Levinas propone una conciencia nointencional (6), donde lo otro conserve su otredad o alteridad y mi respuesta sea no de dominio sino de obediencia. Ante el privilegio dado a través de la historia a la teología, la epistemología, la metafísica, Levinas sostendrá que el verdadero privilegio lo tiene la ética; para él, la ética es la filosofía primera.
\end{abstract}

\title{
II. EL CONCEPTO "MORADA"
}

Como ya se había anunciado, Levinas hace un desarrollo del concepto Morada en su obra Totalidad e Infinito, más específicamente, en el segundo apartado: Interioridad y economía. Previamente, Levinas había planteado la caracterización de dos de sus conceptos indispensables a la hora de acercarnos a su obra, a saber: Mismo y Otro. En Interioridad y economía Levinas conserva su intento por zafarse de la tradición filosófica desde la tradición filosófica misma (7) pero, además, aborda temas típicos de lo que no quedaría atrapado dentro del campo de la conciencia intencional, sino que sería especificidad de una conciencia no-intencional; dentro de estos temas están: la separación como vida (gozo, corporalidad), gozo y representación (alimento, utensilios, sensibilidad), yo y dependencia (alegría y su mañana, amor a la vida). Morada, junto con El mundo de los fenómenos y la expresión, constituye el cierre de esta sección antes de dar paso a lo esencial de la exposición, es decir, antes de plantear su original propuesta El Rostro y la Exterioridad. En síntesis, Morada hace parte de los fundamentos teóricos de su filosofía.

Levinas plantea el concepto a partir de algunos momentos que se irán considerando paulatinamente. En primer lugar, aborda la cuestión de La habitación. Para una persona situada en su cotidianidad (Husserl dirá: en actitud natural), la casa no es un objeto que le pertenece durante un tiempo, que sirve para guarecerse del clima, que alberga la familia, del que se puede disponer en una transacción comercial, al que se puede hacer mejoras con el fin de habitar más cómodamente $y$, desde una perspectiva económica, símbolo de propiedad privada. Pero, dirá Levinas: "presentar la habitación como una toma de conciencia de una cierta conjunción de cuerpos humanos y edificaciones, es dejar de lado, es olvidar el derrame de la conciencia en las cosas, que no consiste, para la conciencia, en una representación de las cosas, sino en una intencionalidad específica de concretización" (8) . No estamos ante la casa de un modo neutral, como no lo estamos ante nada de lo que nos rodea pues todo está mediado por la conciencia que otorga sentido.

La habitación es vista por Levinas como utensilio, es decir, como un instrumental de cosas necesarias para la vida del hombre; sin embargo, dentro de los utensilios, la casa ocupa un lugar privilegiado. La mayoría de personas sentimos la ausencia de la casa especialmente en los momentos de viaje; por más que escuchemos la fórmula "siéntase como en casa", tenemos la impresión de que algo nos falta, un sentimiento de pérdida de autonomía nos acompaña. Podría colegirse que el hombre es un ser arraigado, un ser que en el desplazamiento, forzado o voluntario, siente la nostalgia del punto del que partió. Levinas lo plantea en los siguientes términos: "el papel privilegiado de una casa no consiste en ser el fin de la actividad humana, sino en ser condición y, en este sentido, el comienzo. El recogimiento necesario para que la naturaleza pueda ser representada y trabajada, para que se perfile sólo como mundo, se realiza como casa" (9) . Quizás la palabra focal de la cita la constituya el concepto "recogimiento": la casa es el lugar donde nos recogemos para evaluar la jornada pasada y proyectar el mañana. Anejo al recogimiento está el concepto "intimidad" que, tal vez, es los que perdemos al sentirnos 
Revista Luna Azul - EL CONCEPTO “MORADA” COMO CATEGORÍA POSIBLE P... Página 3 de 10

lejos de nuestra casa.

Levinas es realista en este punto: no es que porque lleguemos a la casa, alcancemos la intimidad; el camino lo plantea de modo inverso, al separarnos, al entrar en la casa, alcanzamos el recogimiento: "el yo existe recogiéndose, se refugia empíricamente en la casa" (10) . En este sentido, la casa deja de ser mero utensilio cuando permite el recogimiento, sólo así se adquiere la significación de Morada. El recogimiento en la Morada, entendida de este modo, es la que lleva a cabo la interioridad.

La segunda implicación del concepto Morada dice relación con lo femenino (11) . La consideración de la casa como Morada implica el recogimiento, es decir, "la suspensión de las reacciones inmediatas que solicita el mundo, en vista de una mayor atención a sí mismo, a sus posibilidades y a la situación" (12). Este planteamiento sugeriría la idea de una casa y en ella un hombre que, sentado en la comodidad de su sillón piensa y se recrea. ¿No es esto, acaso, lo que Levinas critica de la historia de occidente?, ¿no estamos visualizando un hombre solipsista, por más recogido que se halle?

Si algo identifica el pensamiento de Levinas es su obsesión por el otro, no otro abstracto, sino otro que me llama desde su rostro de mujer, de indigente, de sufrimiento; un rostro que "se niega a la posesión, a mis poderes" (13). Pero Levinas no niega, sería ingenuo hacerlo, el campo privilegiado de la identidad, campo que en primera instancia es orgullo del yo en tanto victoria sobre lo anónimo del ser (14). Pero esta victoria primera no puede comprenderse si no hay otra exterioridad a la que trascienda.

El hombre en su sillón podría quedarse perpetuamente pensando si el hambre no le reclamara el alimento. Levinas ve en los nutrimentos una primera posibilidad de salida al mundo en el que se mantienen los dioses epicúreos. La confirmación del yo no viene dada de la serenidad del pensamiento sino del alimento que se goza y que permite mantener la vida: "el Yo perdería así la confirmación que, en tanto que vida de... y gozo de..., recibe del elemento que lo nutre, sin recibir confirmación de otra parte" (15). Este planteamiento resignifica la naturaleza en tanto ésta deja de ser despensa de la cual me usufructo, como si estuviera allí para satisfacer las necesidades de un yo apetecerte, sino que entre ella y ese yo (que soy yo mismo) se crea un clima de familiaridad y amistad experienciable en la dulzura, "una dulzura proveniente de una amistad con este yo" (16) .

Pero no es en los alimentos, aunque estos aniquilen la prepotencia del yo, donde se plenifica la interioridad pues estos aún permanecen en la esfera del algo, mientras que "la intimidad que ya supone la familiaridad es una intimidad con alguien" (17). De cierto modo, toda intimidad requiere un recibimiento. Aunque esta idea suena paradójica, adquiere sentido pues la presencia del rostro del otro, no en cuanto simple representación, indica también su retirada y su ausencia. Sólo ante la ausencia del otro puedo comprender mi soledad (18), pero a la vez mi absoluta diferencia con él, diferencia que se hace aún más radical cuando el otro que se presenta y se ausenta es la mujer.

En este contexto, la cuestión del otro como infinito adquiere un papel fundamental pues, si bien el rostro del hombre que me encuentro podría compartir conmigo, al menos, la universalidad del género masculino, lo femenino se plantea como infinito misterio, pero no un misterio turbador, sino un misterio que admite el silencio, la discreción: "esta alteridad se sitúa en un plano distinto al lenguaje y no representa de ningún modo un lenguaje truncado, balbuceante, aún elemental. Todo lo contrario, la discreción de esta presencia, incluye todas las posibilidades de la relación trascendente con el otro" (19) .

Hasta ahora se ha hecho una consideración de la casa y de lo que en ella ocurre; se ha visto como un resguardo frente al anonimato de la tierra, el aire, la luz, el bosque, el río; se ha planteado como ruptura de la existencia natural. Sin embargo, la casa no me aísla; "el gozo extático e inmediato al cual -aspirado de algún modo por el abismo incierto del elemento- ha podido entregarse el yo, se aplaza y se demora en la casa. Pero esta suspensión no aniquila la relación del yo con los elementos" (20). Desde la ventana de mi casa veo el mundo que puedo tomar o dejar mediante el trabajo; mejor, veo una naturaleza que gracias al trabajo puedo transformar en mundo. El trabajo adquiere en Levinas una consideración importante. 
Hemos dicho que desde la casa se observa el mundo; desde la casa, además, se va al mundo y lo que de él se saca se trae a la casa a modo de posesión que genera la apariencia de gozo. Para Levinas las posesiones no producen gozo pues este es anterior a cualquier actividad; en sus palabras, "ninguna actividad precede a la sensibilidad" (21) . El gozo que aparentemente dan las posesiones tiene una contrapartida: "poseer al gozar es también ser poseído" (22). Estas citas nos remiten inmediatamente a la magistral composición de Cortázar Preámbulo a las instrucciones para dar cuerda al reloj, incluida dentro de las Historias de Cronopios y de Famas; allí Cortázar expone que mientras nos dan un reloj en nuestro aniversario, a la vez nos están dando un objeto del que empezamos a depender: "no te regalan un reloj, tú eres el regalado, a ti te ofrecen para el cumpleaños del reloj" (23). Desde la cotidianidad, el humor y la metafísica que, como lo afirma Merleau-Ponty, está presente en la literatura (24), Cortázar comparte la misma tesis de Levinas.

Consideremos el primer caso: la mano aprehende las cosas y éstas, en la casa, asumen la categoría de tener. A partir del trabajo, el elemento pierde su ser para servir al gozo de quien la toma: "la posesión neutraliza este ser: la cosa en tanto que tener es un ente que ha perdido su ser" (25) . Perder su ser, como lo anuncia Levinas, es caer en el apeiron, es decir, quedar sin origen, sin sustancia, sin nada a qué aferrarse; quedar como materia primera absolutamente indeterminada. Esta materia aprehendida por el trabajo anuncia su anonimato en tanto permanece indefinido e incomprensible; de igual modo, renuncia a su anonimato pues queda a disposición de quien la aprehende que es, en definitiva, quien la introduce en el mundo de lo identificable y domeñable.

Analizado este primer caso a partir de la idea de infinito, tan cara a Levinas, podemos sostener que el trabajo define la materia sin recurrir a la idea de infinito. La relación hombre-cosa no es una relación cara-a-cara; la mano, cuando se acerca al elemento, lo hace con un fin, es decir, "con un objetivo, objetivo de la necesidad y no con un infinito respeto al cual se definiría la cosa" (26). En vez de ser cara-a-cara la relación con la materia se plantea en términos de resistencia; sin embargo, la materia no resiste el doblegar desde un rostro o una idea, "el trabajador lo llevará a cabo y ella no se opone frontalmente, sino como abdicando ya ante la mano que busca el punto vulnerable que, astuta y con malas artes, la alcanza lateralmente" (27). La cosa doblegada es llevada a la morada y se torna mueble, cosa transportable que guarda relación con el cuerpo. La cosa, alejada de su contorno natural, convertida en apeiron, adquiere su sustancia en el ofrecer a la mano que toma y lleva.

Pero el segundo polo de la relación también hay que explorarlo. Si bien Levinas ha planteado que mediante el trabajo la cosa es sacada de su oscuridad, de su apeiron, a la mano que la lleva a la morada, también esa cosa, aunque anunciante mudo y ausente de su independencia, teje relaciones con el cuerpo del dispositor: "lo otro en lo que se regocija -los elementos- no está inicialmente en su favor ni en su contra (...) Pero soberanía del yo que vibra en el gozo, tiene como particularidad que se baña en un medio y, por esto, sufre influencias" (28). El gozo, que se había planteado como sensibilidad autárquica a toda actividad, adopta en este caso una postura ambigua pues empieza a ser determinado por lo que él no es. No es que se produzca de modo violento, el desplazamiento del gozo al gozo por las cosas es visto por Levinas como un dulce veneno que se infiltra dulcemente en la vida.

Vida para Levinas es cuerpo: "no solamente cuerpo propio en el que despunta su suficiencia, sino encrucijada de fuerzas físicas, cuerpo-efecto" (29). Pareciera que la negatividad de la alienación contribuyera a forjar hombres y mujeres dependientes de las cosas y, en esa medida, esclavos. La libertad es vista aquí como un equívoco alojado en el cuerpo. Somos cuerpo y, por ende, somos dueños de nosotros mismos pero, a la vez, estamos sostenidos sobre una tierra que nos brinda todo lo vital. Podríamos decir que es una situación embarazosa, sin embargo, el embarazo no remite a mera dependencia, también "hace la felicidad de aquel que lo goza" (30) .

¿Qué tiene que ver esto con la Morada? Pues bien, si la Morada hace posible la adquisición y el trabajo, ella hace posible, además, que el hombre no sucumba en la soledad de su conciencia. Mediante la Morada, el hombre se comprende no como una conciencia que se encarna en un cuerpo, sino, por el contrario, como un aplazamiento de la corporeidad del cuerpo y tal aplazamiento ocurre en el tiempo. La mano que se dirige a la máquina, como tanteando en ella el fin, no como mero acto mecánico de accionar, es 
Revista Luna Azul - EL CONCEPTO “MORADA” COMO CATEGORÍA POSIBLE P... Página 5 de 10

un lanzamiento hecho al vacío, a la aventura: "el tanteo revela esta posición del cuerpo que a la vez se integra en el ser y permanece en sus intersticios, siempre invitado a franquear una distancia a la aventura, sosteniéndose en él completamente solo: la posición de un ser separado" (31) .

Cada una de las reflexiones anteriores ha preparado la posibilidad suprema de la Morada, es decir, la posibilidad de acoger al otro que se me presenta en mi casa, al abrirle mi casa. El otro no es la piedra que cavo, o el árbol al que arranco su fruto, o el río sobre el que me transporto; el otro no es el mueble al que cambio de lugar, o al que desecho. El otro es rostro que se manifiesta, epifanía de un rostro que me cuestiona, me aborda, escapa a mi posesión, me habla.

En Levinas el lenguaje es un problema central (32); no se trata de significaciones o acuerdos. En el lenguaje ve Levinas el "cuestionamiento del yo, coextensivo de la manifestación del Otro en el rostro" (33). El rostro del Maestro encarna, desde su infinitud y altura, la trascendencia misma de su palabra, la exterioridad. El trato con el otro, el comercio con su infinitud, haría entender de modo ingenuo cómo el otro cabría en mi totalidad, a sabiendas que "la relación con el Otro hace estallar el tope de la totalidad" (34) . El otro no se manifiesta como otro al que tengo que enfrentarme sino como Maestro que enseña, no conquista. El pensamiento pedagógico de Levinas, abordado por algunos estudiosos de su obra (35) remite a una filosofía que se funda en lo antedicho. Para Levinas, "la enseñanza no es una especie de género llamado dominación, una hegemonía que funciona en el seno de una totalidad, sino la presencia de lo Infinito que hace saltar el círculo cerrado de la totalidad" (36) .

Todo en Levinas remite a la ética. El encuentro con el otro, que se prefigura en la relación pacífica, se produce en el lenguaje que, como habíamos dicho, no es un simple juego de sintaxis o reglas formales, sino "contacto a través de una distancia, relación con lo que no se toca, a través de un vacío" (37). Es en el lenguaje donde se expresa la exterioridad absoluta y en el conversar se da el movimiento que retoma y descifra los signos que cada hablante emite (38). Pero el rostro que veo y escucho es recibido en mi casa, no desde la indigencia o en un territorio neutral, "el recogimiento en una casa abierta al Otro -la hospitalidad- es el hecho concreto e inicial del recogimiento humano y de la separación, coincide con el Deseo del Otro absolutamente trascendente" (39) . Contrario a lo que pudiera pensarse, la casa, ante la presencia del rostro, pierde todo viso de raíz, de instalarse; la casa indica excedencia de la relación con el otro.

Finalmente, como la relación con el otro acaece en el mundo, tal relación consiste en "decir el mundo al Otro" (40). No nos referimos a un decir que opera con nombres universales, como poniendo en común un sentido generalizado, un sentido que el otro comparte. El decir el mundo es ofrecer el mundo al otro, una donación original: "los análisis del lenguaje que tienden a presentarlo como una acción sensata entre otras, desconocen eficazmente este ofrecimiento del mundo, este ofrecimiento de contenidos que responde al rostro del Otro o que lo cuestiona" (41). Aquí podría situarse la esencia de la ética que, más que ver el rostro como mera trascendencia óptica, de lo que se trata es de, al ver al rostro, hablar del mundo como primer gesto ético.

\section{III. "MORADA" COMO CATEGORÍA PARA LA ÉTICA AMBIENTAL}

Como se había planteado en la introducción, una ética ambiental puede adoptar el concepto levinasiano Morada como categoría fundante en su conceptualización. Luego de presentar el desarrollo que hace Levinas, adobado con la experiencia que nos es cotidiana, podemos establecer algunos núcleos que, más que programáticos en su primera versión, tendrían una connotación de generadores de discusión.

El primer aspecto a considerar será un retorno a lo que Heidegger caracteriza como Serenidad (42). Aunque en ocasiones intentamos recuperar nuestro pensar auténtico alejándonos de la cultura de la velocidad, aunque cada vez el "campo", como sitio de recreo o habitar, pareciera una opción excelsa para el reencuentro con nuestras raíces, anhelando el nomadismo prehistórico; aunque la idealización de la vida simple haya generado diversos movimientos como el hippismo o el arte Naïf, el llamado se mantiene pues es en el corazón (cœur para Heidegger (43) ), en la interioridad que proclama Levinas donde puede dotarse de sentido el espacio vital que habitamos. 
Revista Luna Azul - EL CONCEPTO “MORADA” COMO CATEGORÍA POSIBLE P... Página 6 de 10

No. 25, Julio - Diciembre 2007

Ahora bien, sería ingenuo plantear una ética ambiental desde un pensar de un sujeto aislado en el sillón de su casa, así su pensar sea un pensar poético, así lo que esté considerando en su reflexión sean modos de salvar el planeta. Ese sujeto que se refugia en su habitación del ruido del mundo y de la presencia de los otros que le son extraños, encuentra en ese recinto la familiaridad de los alimentos que lo nutren y la presencia/ausencia de la mujer que lo espera o que también llega pero que, en cualquier caso, posibilita el acontecer del recibimiento. Tanto los nutrimentos como el rostro femenino permiten mirar el mundo y el otro, no desde la abstracción, sino desde la concreción. El planteamiento ético levinasiano, con su terminología cotidiana (gozo, dulzura, soledad) rompe con cualquier intento de plantear la relación ecológica como un discurso vacío y se interna en lo más íntimo del hombre: su morada, su alimento, su mujer.

Asegurada la interioridad, Levinas anuncia la Morada como espacio separado del mundo $y$, a su vez, trinchera desde la cual se proyecta. El proyectar hace que nuestro trabajo acceda al mundo natural y lo aprehendamos según nuestras necesidades. La cuestión es la siguiente: ¿hasta qué punto las necesidades son necesidades? El dilema que se plantea al ideal de progreso radica en sopesar hasta dónde la naturaleza debe explotarse en aras del desarrollo; sin embargo, el ideal de desarrollo está sustentado en un conjunto de necesidades cada vez más inalcanzables y absurdas.

Al preguntarse retóricamente si se prefiere este mundo con Internet, móviles hiperfuncionales, transportes eficientes, empaques resistentes, artefactos electrónicos, etc., a la época de los cavernícolas, obviamente la respuesta es predecible; pero la pregunta esencial será si todas las necesidades que nos creamos (o que son creadas por los miles de mensajes que a diario aparecen en los medios) son auténticas necesidades o son sólo una forma de acumular y pretender gozo. Aún en el caso extremo que todas nuestras necesidades fuesen necesidades, cabría preguntarse hasta qué punto la concepción de las cosas como muebles ha hecho que, al carecer de valor en sí, se tornen nuevos objetos desechables, fáciles de eliminar de nuestra casa; y, en ese caso, la pregunta debería dirigirse hacia la recuperación del carácter sacralizado de la naturaleza y la necesidad de comprendernos como un todo vital no disponible a los caprichos consumistas.

La reflexión ética del medio ambiente deberá, igualmente, repensar la cuestión del trabajo. Pareciera que desde Marx no habría que decir nada nuevo o, a lo sumo, conformarnos con lo que los sociólogos arguyan. La ética del trabajo tendrá que servir de soporte a la filosofía del medio ambiente, generando nuevas interacciones entre proyecto - trabajador - necesidades - mundo. Las grandes industrias tendrán que replantear esas interacciones y tomar en serio la brecha beneficio - desastre.

Se ha dicho que la evaluación de las necesidades y la reformulación de las interacciones son un aspecto urgente en nuestra relación con el mundo; sin embargo, no puede obviarse un aspecto constantemente recalcado por Levinas: la Morada ha permitido recogernos en nuestra interioridad pero también nos impulsa a salir al mundo, trabajar y poseer. Las cosas nos producen gozo. La relación es inseparable: si bien nos dirigimos a las cosas y las tomamos, a su vez ellas nos producen felicidad y nos advierten que dependemos de ellas, y que nuestro cuerpo, que es nuestra vida, sólo es posible gracias a ellas.

En el fondo de este planteamiento se halla una cuestión esencial y es que un pensamiento que se complace en sí mismo, que concibe el mundo desde la mera óptica de su gozo, que entiende el mundo como mero depósito al cual dirigirse cuando sienta necesidad o, incluso, sin sentirla, se olvida de que depende de lo exterior a él y no sólo para satisfacer sus deseos, sino para conservarse, para mantener su vida. Las políticas de explotación aplican la lógica del pensamiento como centro.

En estos días se asiste al debate sobre la explotación carbonífera en Colombia. Las empresas extractoras construyeron puertos en sitios turísticos de la Costa Atlántica y, para transportar el carbón de las minas al puerto, se requieren camiones gigantes o locomotoras con varios vagones. Los denunciantes de este hecho sostienen que esta práctica afecta tanto el paisaje natural como la salud de los habitantes (por el polvillo que levanta), y la empresa turística. La respuesta oficial, entendible desde la lógica dominante, sostiene que el mercado del carbón tendrá vigencia sólo veinticinco años y, 
Revista Luna Azul - EL CONCEPTO “MORADA” COMO CATEGORÍA POSIBLE P... Página 7 de 10

No. 25, Julio - Diciembre 2007

por ende, necesita acelerarse su comercialización.

Ejemplos como estos son corrientes en nuestra América de venas abiertas. La reflexión debe estar dirigida a la consideración de la dependencia con el mundo y a las prácticas que descentren el privilegio del pensamiento. La consideración del cuerpo que se alimenta y se baña con las cosas, del cuerpo que sufre un clima ardiente que le impide caminar, del cuerpo que respira con dificultad, hará que se incube una ética del cuidado y el gozo, generando actitudes donde la sensibilidad insufle la razón (44) .

Roto todo privilegio del ego conquistador, anclados en la presencia del mundo que se nos abre a nuestro gozo y alimenta nuestro cuerpo, podemos abrirnos a la relación más sublime pero más escondida en muchas consideraciones ambientales: la relación cara-acara. La ética ambiental, una vez considerados los aspectos anteriores, comprende que es la relación con el Otro la que merece especial atención.

Las cifras de muertes violentas y desapariciones dan a entender que la destrucción de nosotros mismos está causando tanto daño como los más graves abusos al ecosistema. La recuperación de la trascendencia del otro, el reclamo inscrito en su rostro (rostro que tiene una marca como la de Caín que anuncia el "no matarás") señala que sobre él no puedo poder. La violencia ejercida al cuerpo y la violencia que se aloja en el lenguaje, hacen necesario recobrar, además, una ética de la conversación, no como una reflexión autónoma, sino como parte del proyecto ambiental que ve en la persona el eje de su estudio.

\section{CONCLUSIÓN}

El considerar la categoría Morada bajo la óptica de una ética ambiental, apenas insinuada, ha permitido dar un nuevo sentido a la casa y comprender, desde ésta, las interacciones que se tejen entre el hombre y su mundo. Si nos obsesionáramos con el oikos y lo seguimos dotando de sentido, tendremos una reflexión ecológica que integre variados elementos sin perder de vista que la ética constituye un puntal destacado y digno de toda consideración interdisciplinaria.

\section{BIBLIOGRAFÍA}

- Aguirre, J. C. El escándalo de la soledad; reflexiones en torno al concepto de tiempo en Levinas. En: La temporalidad humana, asedios desde la fenomenología y la hermenéutica. Popayán: Universidad del Cauca, 2007.

- Aguirre, J. C. Estatus epistemológico de la conversación y sus aportes a la práctica investigativa. En: Revista Cinta de Moebio (Universidad de Chile), No. 25, marzo de 2006.

- Cortázar, J. Historia de Cronopios y de Famas. Madrid: Suma de Letras, 2000.

- Chanter, T. Time, Death, and the feminine: Levinas with Heidegger. Stanford: Stanford University Press, 2001.

- Derrida, J. Violencia y metafísica; ensayo sobre el pensamiento de Emmanuel Levinas. En: La escritura y la diferencia. Barcelona: Anthropos, 1989.

- Dussel, E. Método para una Filosofía de la Liberación. Salamanca: Sígueme, 1974.

- Heidegger, M. La época de la imagen del mundo. En: Caminos de bosque. Madrid: Alianza, 1998.

- Heidegger, M. Serenidad. Barcelona: Serbal, 1994.

- Heidegger, M. ¿Y para qué poetas? En: Caminos de bosque. Madrid: Alianza, 1998.

- Levinas, E. De la existencia al existente. Madrid: Arena Libros, 2000.

- Levinas, E. De otro modo que ser o más allá de la esencia. Salamanca: Sígueme, 1987.

- Levinas, E. La conscience non-intentionnelle. En: Entre nous; essais sur le penser-a-L'autre. Paris : Éditions Grasset \& Fasquelle, 1991.

- Levinas, E. Réflexions sur la "Technique" phénoménologique. En: En découvrant l'existence avec Husserl et Heidegger. Paris : Librairie Philosophique J. Vrin, 1967. 
Revista Luna Azul - EL CONCEPTO “MORADA” COMO CATEGORÍA POSIBLE P... Página 8 de 10

- Levinas, E. Totalidad e Infinito; ensayo sobre la exterioridad. Salamanca: Sígueme, 1977. p. 170.

- Lopes Nunes, E. O outro e o rostro; problemas da Alteridade em Emmanuel Levinas. Braga: Publicações da Facultade de Filosofia da UCP, 1993.

- Maffesoli, M. Elogio de la razón sensible. Barcelona: Paidós, 1997.

- Maldonado-Torres, N. y Schiwy, F. La topología del ser y la geopolítica del saber. Modernidad, imperio, colonialidad. En: (Des)colonialidad del ser y del saber (videos indígenas y los límites coloniales de la izquierda en Bolivia). Buenos Aires: Ediciones del Signo, 2006.

- Merleau-Ponty, M. La novela y la metafísica. En: Sentido y sinsentido. Barcelona: Península, 2000.

- Valevičius, Andrius. Afterword: Emmanuel Levinas, the multicultural philosopher. En: Continental Phylosophy Review 31: 11-14, 1998.

\section{NOTAS}

1. Licenciado en Filosofía de la Universidad Santo Tomás (Bogotá). Magíster en Filosofía de la Universidad de Caldas. Miembro del Círculo Latinoamericano de Filosofía (CLAFEN). Docente de planta del Departamento de Filosofía de la Universidad del Cauca.

2. En varios textos de Heidegger puede encontrarse esta idea. Bastaría con remitirnos a La época de la imagen del mundo, donde aparecen claramente las ideas de ciencia, investigación, proyecto. Cf. Heidegger, M. La época de la imagen del mundo. En: Caminos de bosque. Madrid: Alianza, 1998.

3. Además de la recurrencia a la fenomenología en los diversos análisis que realiza Levinas, un acercamiento al método fenomenológico lo encontramos en Réflexions sur la "Technique" phénoménologique. Pese a las diferencias entre Levinas y Husserl, sostiene Levinas que en fenomenología más que una exégesis de Husserl o de la historia de sus escritos, lo que se hace es abordar las cuestiones de un modo peculiar. Cf. Levinas, E. Réflexions sur la "Technique" phénoménologique. En: En découvrant l'existence avec Husserl et Heidegger. Paris : Librairie Philosophique J. Vrin, 1967. p. 111.

4. Para Valevičius, aunque se dice que Levinas se conoce como un filósofo de cuatro culturas: ruso, judío, alemán y francés, realmente debería decirse que es un filósofo de cinco culturas pues él también escribió en lituano, afianzando más su imagen de filósofo multicultural. Cf. Valevičius, Andrius. Afterword: Emmanuel Levinas, the multicultural philosopher. En: Continental Phylosophy Review 31: 11-14, 1998. p. 11. Este elemento sería importante tenerlo en cuenta a la hora de sostener debates con algunos pensadores de la corriente descolonial, por ejemplo, con Nelson Maldonado-Torres quien en su texto La topología del ser y la geopolítica del saber. Modernidad, imperio, colonialidad afirma: "La geopolítica filosófica de Levinas era diferente de la de Heidegger. Podía imaginar a Atenas y Jerusalén, una al lado de la otra, como base de Occidente. La cuestión es el grado al que este matrimonio respondía satisfactoriamente a los desafíos enfrentados por otras regiones y ciudades en el mundo. Mientras Heidegger se aferra al terruño o a la tierra del ambiente rural, al mito de la autoctonía griega y al alemán como el idioma del Volk en el centro de Europa, Levinas abraza más decididamente el cosmopolitismo de la experiencia urbana, pero solamente piensa el griego y el hebreo como idiomas legítimos para el pensamiento". MaldonadoTorres, N. y Schiwy, F. La topología del ser y la geopolítica del saber. Modernidad, imperio, colonialidad. En: (Des)colonialidad del ser y del saber (videos indígenas y los límites coloniales de la izquierda en Bolivia). Buenos Aires: Ediciones del Signo, 2006.

5. La cuestión de la luz la introduce Levinas desde sus textos iniciales; para él, "el mundo y la luz son la soledad. Estos objetos dados, estos seres vestidos, son otra cosa que yo mismo, pero son míos. Iluminados por la luz, tienen un sentido y, por consiguiente, son como si vinieran de mí". Levinas, E. De la existencia al existente. Madrid: Arena Libros, 2000. p. 115.

6. Cf. Levinas, E. La consciente non-intentionelle. En: Entre nous; essais sur le penser-a-L'autre. Paris : Éditions Grasset \& Fasquelle, 1991. pp. 132-142.

7. Esta es la crítica que dirige Derrida pues, según él, Levinas queda atrapado en el 
Revista Luna Azul - EL CONCEPTO “MORADA” COMO CATEGORÍA POSIBLE P... Página 9 de 10

mismo lenguaje que pretende superar (Cf. Derrida, J. Violencia y metafísica; ensayo sobre el pensamiento de Emmanuel Levinas. En: La escritura y la diferencia. Barcelona: Anthropos, 1989). Esta crítica de uno de los primeros lectores serios de su obra, hizo que Levinas, luego de su magistral obra Totalidad e Infinito, sorprendiera al público con la publicación de De otro modo que ser o más allá de la esencia.

8. Levinas, E. Totalidad e Infinito; ensayo sobre la exterioridad. Salamanca: Sígueme, 1977. p. 170.

9. Ibíd.

10. Ibíd., p. 171.

11. Levinas ha sido un filósofo inspirador de varios trabajos en torno a la cuestión de lo femenino. Entre los trabajos dedicados a ello está el libro de Tina Chanter: Time, Death, and the feminine: Levinas with Heidegger (Stanford: Stanford University Press, 2001), así como la tesis de Etelvina Pires Lopes Nunes: O outro e o rostro; problemas da Alteridade em Emmanuel Levinas (Braga: Publicações da Facultade de Filosofia da UCP, 1993), específicamente el capítulo $V$ titulado: O outro feminino. En nuestro contexto, el filósofo argentino Enrique Dussel también ha abordado la cuestión, precisamente desde la perspectiva de Levinas; véase, por ejemplo, su manual: Método para una Filosofía de la Liberación (Salamanca: Sígueme, 1974).

12. Levinas, Totalidad e Infinito, op. cit., p. 172.

13. Ibíd., p. 211.

14. Levinas desarrolla esta cuestión a partir de los conceptos hipóstasis e il-y-a. Un desarrollo de estos conceptos se encuentra en: Aguirre, J. C. El escándalo de la soledad; reflexiones en torno al concepto de tiempo en Levinas. En: La temporalidad humana, asedios desde la fenomenología y la hermenéutica. Popayán: Universidad del Cauca, 2007.

15. Levinas, Totalidad e Infinito, op. cit., p. 172.

16. Ibíd.

17. Ibíd.

18. Cuando hacemos referencia a esta categoría, hay que tener en cuenta que en Levinas, la soledad no es un concepto meramente psicológico o sociológico, como carencia de o angustia. Situada en el campo de la hipóstasis, "la libertad en la hipóstasis es también soledad, el sujeto está solo porque es uno. Pero lo que puede ser desesperación para algunos, para Levinas es virilidad, orgullo y soberanía. Así pues, la existencia no es carencia ni trauma, es el triunfo sobre un campo de fuerzas anónimo del cual brota un existente libre". Aguirre, op. cit., p. 160.

19. Levinas, Totalidad e Infinito, op. cit., p. 173.

20. Ibíd., p. 174.

21. Ibíd., p. 176.

22. Ibíd.

23. Cortázar, J. Historia de Cronopios y de Famas. Madrid: Suma de Letras, 2000. p. 28.

24. Cf. Merleau-Ponty, M. La novela y la metafísica. En: Sentido y sinsentido. Barcelona: Península, 2000. pp. 57-78.

25. Levinas, Totalidad e Infinito, op. cit., p. 176.

26. Ibíd., p. 177.

27. Ibíd.

28. Ibíd., p. 181.

29. Ibíd., p. 182.

30. Ibíd.

31. Ibíd., p. 185.

32. Véase por ejemplo el desarrollo que hace alrededor del problema del lenguaje en su obra: De otro modo que ser o más allá de la esencia, especialmente el capítulo cuarto: El Decir y la subjetividad. Cf. Levinas, E. De otro modo que ser o más allá de la esencia. Salamanca: Sígueme, 1987.

33. Levinas, Totalidad e Infinito, op. cit., p. 189

34. Ibíd.

35. Baste citar los títulos del número 22 de la revista Studies in Philosophy and Education (2003), resultado del panel de la Annual Meeting of the American Educational Research Association en New Orleans, Abril, 2000, titulado: "Teaching Otherwise: Levinas and Education": Sharon Todd hizo la introducción y la denominó: Levinas and education: the question of implication; el artículo de Carl 
Revista Luna Azul - EL CONCEPTO “MORADA” COMO CATEGORÍA POSIBL... Página 10 de 10

Anders Säfström se llamó: Teaching otherwise; Gert Biesta hizo una ponencia titulada: Learning from Levinas: a response. Posteriormente, la misma revista en el número 24 de 2005 publicó el artículo de Michalinos Zembylas titulado: $A$ pedagogy of unknowing: witnessing unknowability in teaching and learning. En nuestro contexto, Enrique Dussel, en la obra ya citada, aborda el problema de lo pedagógico en perspectiva levinasiana.

36. Levinas, Totalidad e Infinito, op. cit., p. 189.

37. Ibíd., p. 190.

38. La cuestión de la conversación requiere una reflexión más profunda desde las consideraciones filosóficas alternativas al análisis lógico del lenguaje. Un intento de esto puede encontrarse en: Aguirre, J. Estatus epistemológico de la conversación y sus aportes a la práctica investigativa. En: Revista Cinta de Moebio (Universidad de Chile), No. 25, marzo de 2006.

39. Levinas, Totalidad e Infinito, op. cit., p. 190.

40. Ibíd., p. 191.

41. Ibíd., p. 192.

42. Cf. Heidegger, M. Serenidad. Barcelona: Serbal, 1994.

43. Cf. Heidegger, M. ¿Y para qué poetas? En: Caminos de bosque. Madrid: Alianza, 1998. p. 229.

44. La tesis de la razón sensible ha sido propuesta por Michel Maffesoli quien, desde un enfoque sociológico que reivindica el conocimiento ordinario, aborda temas como: la deontología, la distinción entre razón abstracta y razón interna, la deontología, la fenomenología, la experiencia y la iluminación a través de los sentidos. Cf. Maffesoli, M. Elogio de la razón sensible. Barcelona: Paidós, 1997.

Close Window 